\title{
Haches de pierre. Au Néolithique, les premiers paysans du Tarn
}

\section{Charles-Tanguy Le Roux}

\section{(2) OpenEdition \\ 1 Journals}

Édition électronique

URL : https://journals.openedition.org/rao/1870

DOI : 10.4000/rao.1870

ISBN : 978-2-7535-2790-4

ISSN : $1775-3732$

\section{Éditeur}

Presses universitaires de Rennes

\section{Édition imprimée}

Date de publication : 30 décembre 2012

Pagination : 322

ISBN : 978-2-7535-2641-9

ISSN : 0767-709X

\section{Référence électronique}

Charles-Tanguy Le Roux, « Haches de pierre. Au Néolithique, les premiers paysans du Tarn », Revue archéologique de l'Ouest [En ligne], 29 | 2012, mis en ligne le 30 décembre 2012, consulté le 22 juillet 2021. URL : http://journals.openedition.org/rao/1870 ; DOI : https://doi.org/10.4000/rao.1870

Ce document a été généré automatiquement le 22 juillet 2021.

@ Presses universitaires de Rennes 


\title{
Haches de pierre. Au Néolithique, les premiers paysans du Tarn
}

\author{
Charles-Tanguy Le Roux
}

\section{RÉFÉRENCE}

Servelle C. (dir.), 2011 - Haches de pierre. Au Néolithique, les premiers paysans du Tarn, Castres, CDAT (Comité départemental d'archéologie du Tarn), 756 p., 48 pl. H.-T. (ISBN 978-2-918190-10-3, $35 €$ ).

1 Initialement, cet ouvrage se voulait le catalogue de l'exposition du même nom, préparée elle aussi sous la direction scientifique de Christian Servelle, archéologue à la DRAC de Midi-Pyrénées. Cette manifestation fut inaugurée à Gaillac en octobre 2007 mais, devant cet imposant volume de près de $3 \mathrm{~kg}$ (plus de 800 pages au format carré $245 \times 245 \mathrm{~mm}$ ), on conçoit que la sortie en ait quelque peu tardé. Sous la plume de 44 contributeurs scientifiques, 62 articles s'y organisent en quatre grandes parties au demeurant bien classiques pour un tel sujet: l'environnement des populations néolithiques; le Néolithique du Tarn; la lame de pierre polie; de la pierre au métal. En fait, le contenu dépasse de beaucoup l'annonce du titre car, à côté de présentations ponctuelles ou d'études de cas, on trouve beaucoup de synthèses régionales voire interrégionales d'intérêt général, ce qui justifie amplement la présentation de l'ouvrage dans ces colonnes. Quant à la personnalité bien connue du directeur de publication, "archéologue ouvrier» comme il se présente lui-même en page d'accueil, elle transparaît dans la tonalité générale qu'il a su imprimer à ce colossal travail collectif, en plus de ses multiples contributions personnelles. Il n'est hélas pas possible ici d'analyser chaque article ni même de donner un sommaire complet; nous nous limiterons donc à une présentation générale et à quelques points particuliers.

2 A priori, le cadre départemental peut sembler étroit et artificiel pour un tel projet, surtout pour un département du Tarn partagé entre l'est du bassin aquitain et le sud du Massif central, régions aux histoires géologiques et aux ressources naturelles 
radicalement différentes comme le montre une longue présentation géologique liminaire en trois points. Pourtant, comme le souligne P. Durand (p. 123), ce territoire " est à la confluence de trois grandes régions... atlantique aquitaine... ; Massif central... ; méditerranéenne ", ce qui n'est pas sans conséquences sur le peuplement humain, son insertion dans l'espace naturel et ses affinités culturelles aux différentes époques.

3 La deuxième partie s'ouvre sur un rappel historique incluant la présentation de deux « figures » de l'archéologie tarnaise naissante que furent A. Caraven et P. Thomas. Dans les huit articles traitant de "l'occupation néolithique... », on notera particulièrement la synthèse de K. Gernigon, N. Valdeyron et J. Vaquer sur «Le Néolithique du Tarn dans son cadre méridional », depuis ses premiers indices, ténus mais d'affinités clairement languedociennes (la Molière et Sagnebaude), jusqu'au Chalcolithique avec sa première métallurgie pré-campaniforme (la Vaysonnié, etc.). Au chapitre suivant (« habitat et sépultures »), on notera une synthèse de Y. Fouéré sur " la maison néolithique dans le sud-ouest de la France » (en fait, du Châtelleraudais aux environs de Millau, mais sans exemple disponible pour le Tarn) et la présentation - certes obligée - du mégalithisme tarnais (dolmens et statues-menhirs). À noter la longue dissertation de J. Zammit sur « la violence à la fin du Néolithique » à partir du cas bien connu de l'aven de Mauray.

Comme il se devait, près de 220 pages sont ensuite dédiées à « la lame de pierre polie ». Une première subdivision s'ouvre par trois articles rappelant ce qu'avait été l'outillage lourd à percussion lancée, du Paléolithique inférieur au Mésolithique. Onze contributions abordent ensuite la problématique tarnaise de la hache polie sous ses différents aspects: productions régionales, importations, exportations, utilisations, expérimentations. Parmi celles-ci, l'article de F. Brillois, C. Servelle et J. Vaquer sur "les grandes haches d'origine alpine dans le sud-ouest de la France » nous suggère quelques réflexions :

5 - N'est-il pas un brin simpliste de placer une barre rigide à $14 \mathrm{~cm}$ de long pour séparer haches «d'apparat» et haches «de travail»? N'oublions pas non plus que la beauté d'un poli spéculaire ne nous fascine sur une pyroxénite que dans la mesure où il a été préservé; il pouvait être tout aussi spectaculaire sur d'autres roches aujourd'hui altérées ;

6 - Le sciage latéral des lames "à section équarrie " est-il bien compatible avec la courbure longitudinale - faible mais réelle et régulière - de ceux-ci ( $a$ fortiori pour le «type Pauilhac » dont le tranchant est en outre évasé) ? Des contre-exemples en sont d'ailleurs fournis par C. Servelle lui-même un peu plus haut (p. 454, 461);

7 - L'origine bretonne prêtée aux lames à carène faciale (par exemple Pezens) ne s'appuie-t-elle pas trop sur un unicum régional, celle (et non celles) du Mané-erHroeck?

8 - Enfin, l'origine alpine des roches vertes nobles, présentée comme un quasi postulat, aurait mérité d'être explicitement validée par un test simple, celui de la densité : à l'occasion du PCR «Étude pétrographique et archéologique des bracelets et haches polies en roches « tenaces » du Poitou-Charentes et des régions voisines» dirigé par B. Bourgueil, J.-P. Floc'h a en effet pu proposer « la présomption d'une origine alpine pour toutes les pièces... dont la densité dépasse 3,25 », les discriminant ainsi des pyroxénites sodifères du domaine hercynien (rapport d'activité 2004 - pétrographie, p. 1-4).

Une troisième subdivision traite de « la hache polie en dehors du Tarn». En fait, seuls quelques productions considérées comme typiques y sont abordées : le nord du Bassin 
aquitain (en fait, du Grand-Pressigny au Bergeracois), le domaine alpin, Jablines, Plussulien, le Maroc. Mais on y appréciera aussi un rapprochement trop rarement effectué, celui avec "les "outils avec tranchant" en coquille des Antilles précolombiennes... ", proposé par N. Serrand.

La quatrième partie s'organise en deux volets. Le premier s'ouvre sur la suite directe donnée régionalement aux lames de pierre polie, à savoir les premières haches en cuivre; distribution, typologie et technologie sont abordés en deux articles. Le second ( "Des outils de pierre pour les bronziers et les forgerons ») nous semble quelque peu " solliciter » la pièce de Lavaur (aux conditions de découverte quasi inconnues). Ce type de "hache à méplat» se rencontre sporadiquement comme évoqué par l'auteur, y compris dans des régions n'ayant pas connu une métallurgie aussi précoce que le Tarn. Les typologies sont variés (ce qui plaide en faveur d'un réemploi) mais méplats et/ou rainures sont en général patinés (ce qui semble écarter des réappropriations modernes). Comme pour les pièces présentées (Lavaur et Magrin), les surfaces sont en général dépourvues des esquillures que n'auraient pas manqué de provoquer le martelage d'une surface dure. Personnellement, nous inclinerions plutôt en faveur d'un travail de brunissage ou de bourrellerie, les stries latérales (que l'on peut trouver indépendamment du méplat) pouvant être liées à l'assouplissement de fils ou de fines lanières; en tout état de cause, une étude tracéologique générale de ces objets mérite d'être tentée. Après la présentation de l'exceptionnelle parure de la Vaysonnié, nous partons dans les Hautes-Alpes avec la mine de Saint-Véran avant de descendre le fil du temps, à travers l'âge du Bronze et jusqu'à la période romaine. Quant au deuxième volet, " hache de pierre oubliée, hache de pierre imaginée », il nous transporte avec délices dans le monde des traditions populaires puis dans celui des arts: peinture, fiction (littéraire ou graphique), cinéma scientifique.

À la fin de tout cela, un cahier en couleurs reprend les meilleures des illustrations qui avaient accompagné les différents textes en noir-et-blanc. Au moment de refermer ces pages, le lecteur est un peu abasourdi par tant d'information mais admiratif devant la somme d'informations et de réflexions ainsi rassemblées. On pourra certes regretter que pas le moindre résumé en anglais (ni en espagnol) ne vienne faciliter la diffusion internationale de cette somme mais, en ces temps difficiles, on appréciera l'investissement humain - et aussi financier - que représente un tel ouvrage. Chacun aura gré pendant longtemps au comité départemental d'Archéologie, au conseil général du Tarn et à la DRAC de Midi-Pyrénées d'avoir uni leurs efforts pour un si beau résultat à un prix aussi compétitif. 